\title{
Spinach and Chive for Kidney Tubule Engineering: the Limitations of Decellularized Plant Scaffolds and Vasculature
}

\author{
Katja Jansen, ${ }^{1}$ Marianna Evangelopoulou, ${ }^{1}$ Carla Pou Casellas, ${ }^{1}$ Sarina Abrishamcar, ${ }^{1}$ Jitske Jansen, ${ }^{2,3}$ \\ Tina Vermonden, ${ }^{4}$ and Rosalinde Masereeuw ${ }^{1,5,6}{ }_{(\mathbb{C}}$
}

Received 29 September 2020; accepted 8 December 2020; published online 28 December 2020

\begin{abstract}
Tissue decellularization yields complex scaffolds with retained composition and structure, and plants offer an inexhaustible natural source of numerous shapes. Plant tissue could be a solution for regenerative organ replacement strategies and advanced in vitro modeling, as biofunctionalization of decellularized tissue allows adhesion of various kinds of human cells that can grow into functional tissue. Here, we investigated the potential of spinach leaf vasculature and chive stems for kidney tubule engineering to apply in tubular transport studies. We successfully decellularized both plant tissues and confirmed general scaffold suitability for topical recellularization with renal cells. However, due to anatomical restrictions, we believe that spinach and chive vasculature themselves cannot be recellularized by current methods. Moreover, gradual tissue disintegration and deficient diffusion capacity make decellularized plant scaffolds unsuitable for kidney tubule engineering, which relies on transepithelial solute exchange between two compartments. We conclude that plant-derived structures and biomaterials need to be carefully considered and possibly integrated with other tissue engineering technologies for enhanced capabilities.
\end{abstract}

KEYWORDS: Tissue engineering; Regenerative medicine; Proximal tubule; Plant scaffolds; Decellularization.

\section{INTRODUCTION}

To mimic native tissue, organ-specific cells are usually seeded onto or into scaffolds with a defined 3D structure and stimulated with growth factors, physicochemical factors, and perfusion. To date, cornea, skin, and articular joint tissue are among the most advanced engineered tissue constructs due to their relatively simple architecture (1). In contrast, the kidney is one of the most complex ones; structural and functional complexity make it impossible to recapitulate its original architecture with traditional top-down approaches (e.g.,

${ }^{1}$ Division of Pharmacology, Utrecht Institute for Pharmaceutical Sciences, Utrecht University, Utrecht, The Netherlands.

${ }^{2}$ Department of Pathology, Radboud Institute for Molecular Life Sciences, Radboud university medical center, Nijmegen, The Netherlands.

${ }^{3}$ Department of Pediatric Nephrology, Radboud Institute for Molecular Life Sciences, Radboud university medical center, Amalia Children's Hospital, Nijmegen, The Netherlands.

${ }^{4}$ Division of Pharmaceutics, Utrecht Institute for Pharmaceutical Sciences, Utrecht University, Utrecht, The Netherlands.

${ }^{5}$ Division of Pharmacology, Utrecht Institute for Pharmaceutical Sciences, Universiteitsweg 99, 3584 CG, Utrecht, The Netherlands.

${ }^{6}$ To whom correspondence should be addressed. (e-mail: r.masereeuw@uu.nl) micro-molding or 3D bioprinting) (2). The explosive advancement of organoid technology, a bottom-up approach in regenerative medicine, reflects our dependency on the power of nature: the most sophisticated tissues currently created in a dish are the result of cellular self-organization $(3,4)$. However, despite being complex in structure, kidney organoids are still immature and limited in size, and they lack a functioning drainage system. An intermediate tissue engineering approach is the de- and recellularization of existing tissue, which yields whole organ scaffolds with intact extracellular matrix (5-7). In a proof-of-concept study, recellularized rat kidneys were able to regenerate partial excretory functionality upon recellularization and experimental orthotopic transplantation $(8,9)$. For clinical consideration, however, such system has to be upscaled and optimized further, and also for advanced in vitro modeling, whole scaffolds are no sustainable option, except when cut into multiple scaffold slices (7). In 2017, Gershlak et al. drew attention to the concept of crossing kingdoms in tissue engineering by using plant-derived decellularized scaffolds for the fabrication of lab-grown organs with perfusable vasculature (10). In this and another follow-up study, the research group showed successful decellularization of various plant leaves and roots (i.e., spinach, parsley, Artemisia annua leaves, anthurium waroqueanum, Calathea zebrina, bamboo, 
orchid, vanilla, and peanut hairy roots); recellularization was proven with several human cell sources (i.e., human umbilical vein endothelial cells, dermal fibroblasts, mesenchymal stem cells, and pluripotent stem cell-derived cardiomyocytes) (10, 11). In fact, the concept of using decellularized cellulose for cell cultures has been developed earlier with apple hypanthium, for which cell adhesion, invasion, and proliferation have been shown with NIH3T3 fibroblasts, mouse $\mathrm{C} 2 \mathrm{C} 12$ muscle myoblasts, and human HeLa epithelial cells. Moreover, biocompatibility and active blood vessel formation have been demonstrated after implantation in vivo $(12,13)$. Here, we adopted and evaluated the crossing kingdoms principle for in vitro modeling of kidney tubules. These studies showed that various mammalian cell types attach and grow on plantderived cellulose scaffolds, but we want to stress that tissuespecific requirements must be considered. For instance, to facilitate active secretion of metabolic end products and drugs, engineered kidney tubules require a thin and smallsized tubular scaffold that separates the inner and outer compartment through a monolayer of kidney proximal epithelial tubular cells, preferably with drainage capacity. For this, we hypothesized that the vasculature of decellularized spinach leaves or hollow chive stems could serve as such scaffolds and examined them for functional requirements.

\section{METHODS}

\section{Scaffold Decellularization}

Spinach leaves and chive stems, obtained from a local store, were placed in n-hexane on a shake rocker for $30 \mathrm{~min}$ to remove the cuticle. After rinsing with distilled water, they were placed on a perfusion pump or the shake rocker with daily refreshed $5 \%(\mathrm{v} / \mathrm{v})$ sodium dodecyl sulfate (SDS) for 7 days. In parallel, a freshly isolated kidney from a healthy male surplus Wistar rat was perfused using a 5-day 1\% (v/v) SDS and 30-min 1\% (v/v) Triton X-100 decellularization protocol as described earlier (14). Following the protocol for plant tissue after 5\% (v/v) SDS treatment, all plant samples were first washed with $10 \%(\mathrm{v} / \mathrm{v})$ sodium chlorite and $1 \%$ (v/v) Triton-X100 for 5 days and ultrapure water for up to 7 days until samples were translucent. Until recellularization, plant samples were stored in $70 \%$ ethanol at room temperature, whereas the decellularized rat kidney was frozen at $-20{ }^{\circ} \mathrm{C}$.

\section{Scaffold Recellularization}

Before recellularization, the samples were sterilized with $365 \mathrm{~nm}$ UV light (2.6 mW cm - 2, UVP CL-1000 for $15 \mathrm{~min}$ ) and washed with sterile Hanks' Balanced Salt Solution (HBSS) overnight. Kidney tissue was sliced into $150 \mu \mathrm{m}$ pieces and sterilized with $0.2 \%(\mathrm{v} / \mathrm{v})$ peracetic acid in $4 \%$ (v/v) ethanol for $10 \mathrm{~min}$ (7). While adhesive coating was unnecessary for kidney tissue, decellularized plant samples were coated for $4 \mathrm{~h}$ with $2 \mathrm{mg} / \mathrm{mL}$ 1-3,4dihydroxyphenylalanine (L-DOPA, Sigma Aldrich) dissolved in $10 \mathrm{mM}$ Tris buffer at $\mathrm{pH} 8.5$, which was pre-incubated at $37{ }^{\circ} \mathrm{C}$ for $45 \mathrm{~min}$ and $0.2 \mu \mathrm{m}$ filter-sterilized (15). After thorough sample washing with HBSS, 500.000 parent or tetramethylrhodamine-isothiocyanate (TRITC)-labeled conditionally immortalized proximal tubule epithelial cells (ciPTEC) were seeded onto a rat kidney slice in an ultralow attachment plate or injected into the spinach petiole or chive stem using a 22 gauge injection needle and ciPTEC medium composed as described earlier (7, 16, 17). The ciPTEC cell line was obtained as described by Wilmer et al. with informed consent of the donor and in accordance with the approved guidelines of the Radboud Institutional Review Board. In short, cells exfoliated in the urine of a healthy volunteer were transfected with SV40T and hTERT vectors and subcloned for a homogeneous cell population (16). Chive was turned $180^{\circ}$ after $1 \mathrm{~h}$ and after $2 \mathrm{~h}$; all recellularized samples were submerged in medium and cultured until confluency (16).

\section{Protein Quantification}

Protein quantification was performed with the BCA Protein Assay Kit (Pierce Biotechnology) according to the manufacturer's instructions, and plates were read at $595 \mathrm{~nm}$ using the iMark Microplate Absorbance Reader (Bio-Rad).

\section{Microscopic Imaging}

Before DAPI staining (1:1000, Sigma-Aldrich), cells were fixed with $2 \% w / v$ paraformaldehyde in HBSS and permeabilized with $0.3 \% \mathrm{v} / \mathrm{v}$ triton X-100 in HBSS for $10 \mathrm{~min}$ (Sigma-Aldrich). Microscopic images were taken with a Keyence BZ-9000 fluorescence microscope or confocal microscope Leica TCS SP8 X.

\section{Mechanical Analysis}

The mechanical behavior of decellularized chive was tested under uniaxial tensile loading using a Dynamic Mechanical Analyzer (DMA Q800, TA Instruments). Strain and stress at break were determined from the stress-strain curves.

\section{Diffusion Assay}

A leakage assay was performed in custom-printed flow chambers (Ultimaker 3) on dialysis fibers (MicroPES type TF10 hollow fibers, Membrana GmbH, Germany) and decellularized chive, with $0.1 \mathrm{mg} / \mathrm{ml}$ fluorescein isothiocyanate-inulin (inulin-FITC, Sigma Aldrich) perfusion for $10 \mathrm{~min}$. All results were statistically analyzed using oneway ANOVA (GraphPad Prism 8).

\section{RESULTS}

\section{Successful Application of De- and Recellularization Tech- niques on Spinach Leaves and Chive}

We successfully applied the decellularization technique described by Gershlak et al. to produce plant-derived hollow tubular scaffolds from spinach leaves and chive stems (18). Decellularization by perfusion was much slower for spinach leaves than for the rat kidney, indicating less efficient penetration of the detergent (Fig. 1a). Moreover, decellularization through perfusion led to considerable 
SDS precipitation on the leaf, thus we proceeded with plate rocker incubation and minor adaptations in treatment lengths based on visual progress in decellularization (i.e., 7 days $5 \%(\mathrm{v} / \mathrm{v})$ SDS vs 5 days $10 \%$ (v/v) SDS, 5 days vs 2 days in sodium chlorite and Triton X-100 solution, and up to 7 days vs 2 days in deionized water). Similar to spinach leaves, we observed a gradual decrease in protein content in chive over the course of all washing steps (Fig. 1b). While cells attached to uncoated decellularized kidney slices (Fig. 2a), only few attached to the uncoated luminal chive scaffold wall. Instead, the cells grew in clumps that resided inside the lumen (Fig. $2 \mathrm{~b}-\mathrm{c})$. Fontana et al. used biomineralization or coating with dopamine-conjugated tripeptide Arginine-GlycineAspartate $(R G D)$ peptides for attachment of human mesenchymal stem cells and dermal fibroblasts $(11,18)$, but a simple coating with L-DOPA proved sufficient to create renal cell monolayers. Monolayers already formed $24 \mathrm{~h}$ after seeding but dominated one side of the lumen due to gravity (Fig. 2d). Extended culture time at $33{ }^{\circ} \mathrm{C}$ allowed cell proliferation and closure of the monolayer on the inner scaffold surface.

\section{Leaf Vasculature Appears to Have Anatomical Restrictions for Cell Infiltration}

Renal cells could grow in the lumens of chive and spinach petioles, but they did not reach the spinach leaf vasculature through petiole injection. Despite the vascular recellularization claims by Gershlak et al., we believe that the plant vascular anatomy makes accessibility for cell seeding very unlikely. The petiole cavity is hollow and hence easily perfusable, but the vascular bundles, which form the conducting vessels for nutrients, water, and oxygen transport, are in fact located in the parenchyma next to the petiole cavity. Also in chive, the vascular bundles are located in the cortex, directly below the epidermis (Fig. 3a). The petiole cavities are air-filled, which fulfills three major functions: it saves growth energy, reduces tissue weight, and gives mechanical stability to enable growth in height and size. It is important to note that petioles are not connected to the leaf vasculature, which is separated from the parenchyma by impermeable structures to prevent water loss through diffusion. We suspect that, during decellularization, spinach leaves are not being perfused through the vasculature. More likely, the solution flows through the petiole cavity to enter the leaf parenchyma, either through diffusion or perfusion-induced breaks in the tissue. In accordance, the initial leaf discoloration pattern in Fig. 1a suggests general tissue penetration rather than selective vasculature perfusion. Apart from the lack of a direct connection between the petiole cavity and the leaf vasculature, a closer look at the anatomy of the vascular bundle itself, consisting of xylem and phloem, reveals another major hurdle for vascular recellularization (Fig. 3b). Xylem conducts water through tracheary elements, which are interconnected by areas that lack cell walls, known as perforations. Phloem transports soluble organic compounds through sieve tubes, which are also interconnected by perforations in their end walls to form transport channels $(19,20)$. These sieve-like areas likely trap injected cells. Even if our epithelial cells came through, they would grow over the perforations and hence occlude the vasculature (17). Gershlak et al. did not go into detail on the colonization of the inner surfaces with endothelial cells (10). From our results with epithelial cells, we conclude that recellularization of vasculature bundles in plant-derived scaffolds is unlikely obtainable and shifted focus to chive stems.

\section{Insufficient Scaffold Permeability for Transepithelial Transport Functionality}

With chive as alternative tubular plant-derived tissue, we

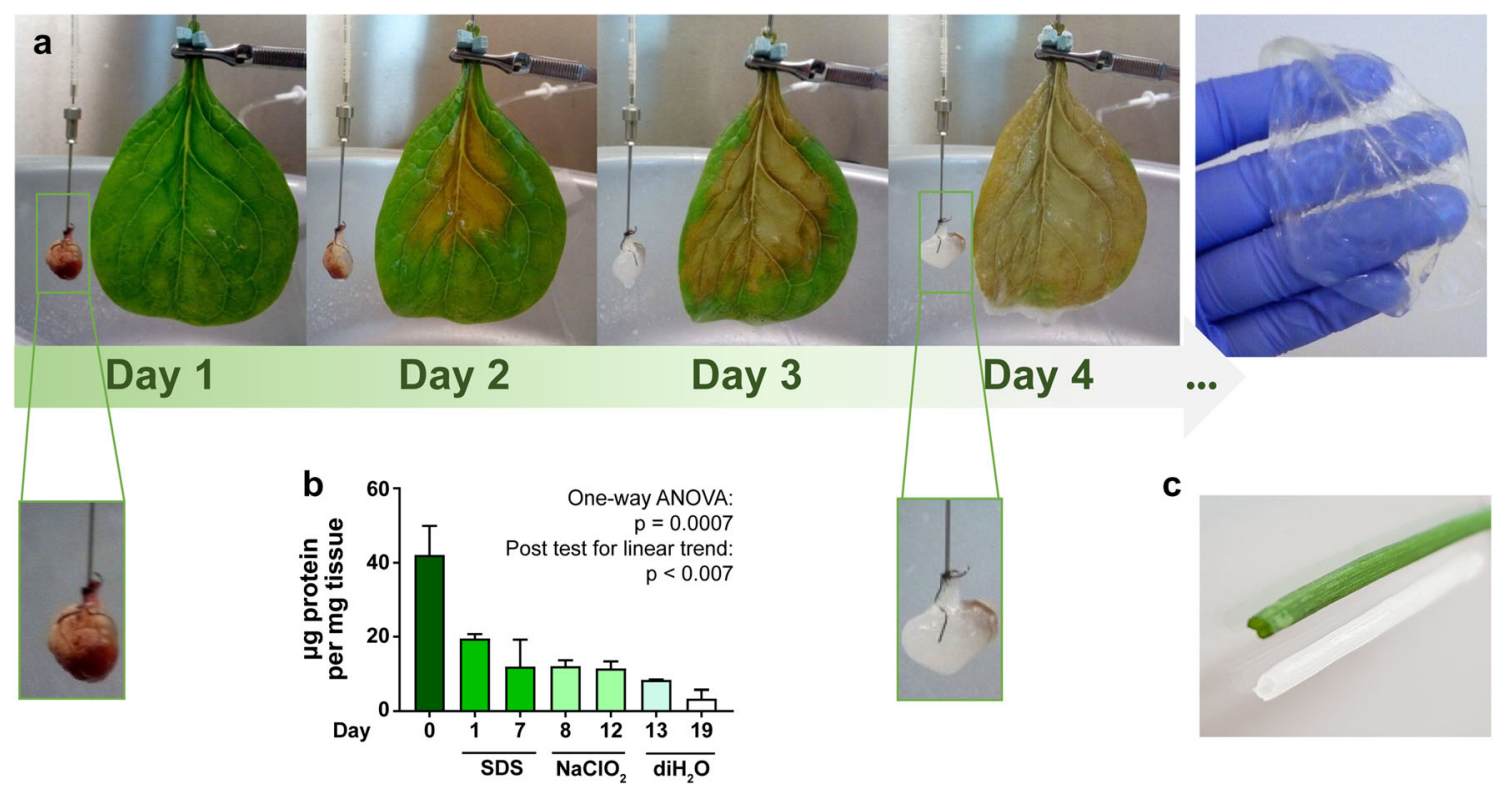

Fig. 1. Decellularization of a rat kidney, spinach leaf and chive. a Decellularization process of a perfused spinach leaf next to a perfused rat kidney. b Protein quantification in chive samples at different steps of the decellularization process $(n=2)$. c Picture of native and decellularized chive 

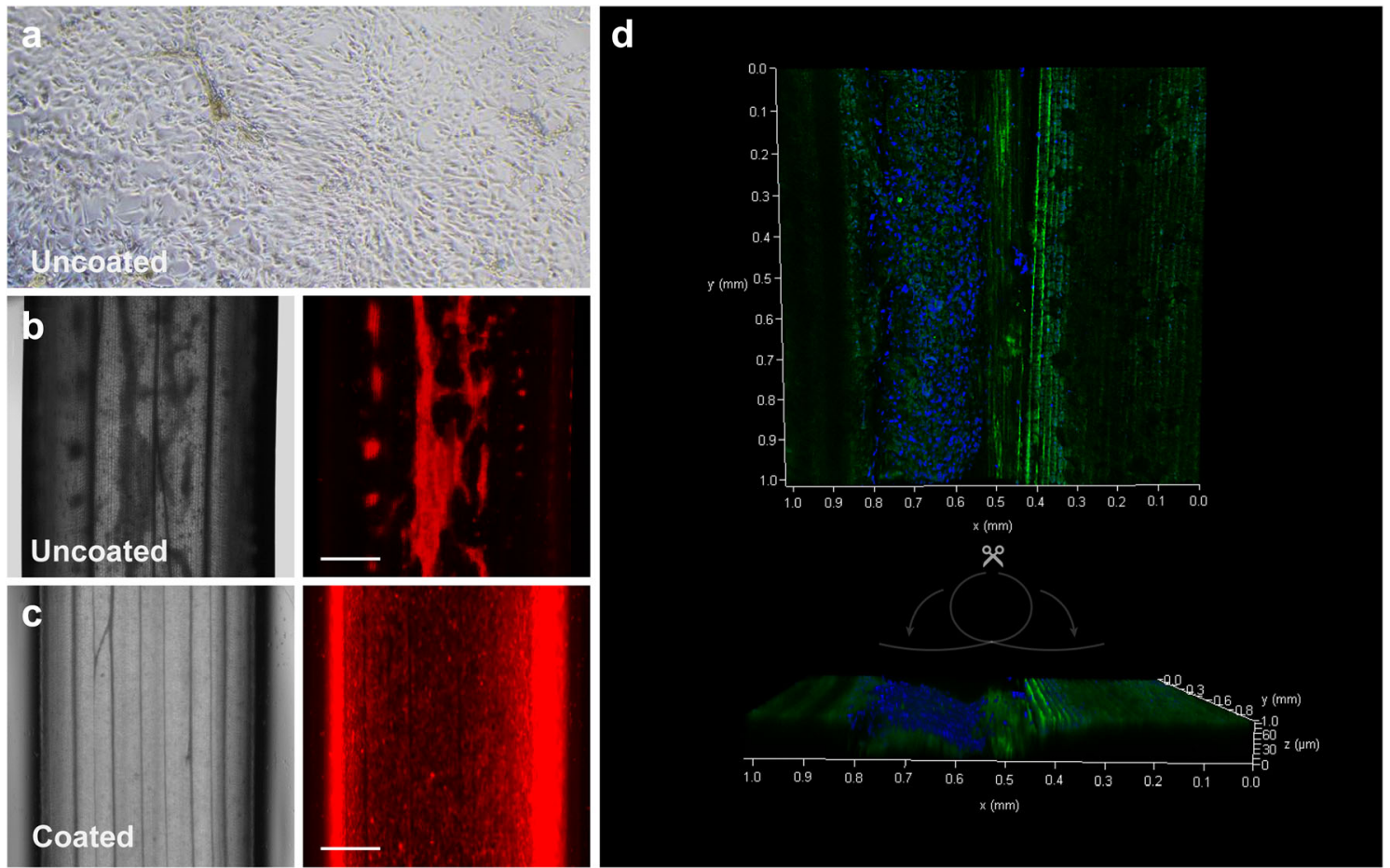

Fig. 2. Recellularization of chive-derived scaffolds with and without biofunctionalization. a Representative brightfield picture of a $150 \mu \mathrm{m}$ rat kidney slice $24 \mathrm{~h}$ culture after recellularization with ciPTEC. b-c Representative micrographs of decellularized uncoated and L-DOPA-coated chive with luminal seeding of TRITC-labeled ciPTEC $(n=3)$. d DAPI staining (blue) of ciPTEC $24 \mathrm{~h}$ after seeding in a cut and open-folded chive (autofluorescence green). Scale bars $=1 \mathrm{~mm}$

faced two other problems. First, although recellularization was performed successfully, both spinach and chive tissue quickly disintegrated in culture. Accordingly, it was not possible to apply traverse tensile loading on chive for mechanical testing; the tissue could only withstand tensile loading in longitudinal direction, along the cellulose fibers. Here, samples broke at quite deviating stress points, but stiffness and elasticity were in the same range as native tissue; stress at break was $0.7 \pm 0.2 \mathrm{MPa}$ compared with $1.1 \pm$
0.2 MPa for native tissue, and strain at break was $20 \pm 13 \%$ compared with $13 \pm 3 \%$ in native tissue (Fig. 3c). High variability between samples can be ascribed to the natural character of the scaffold source. The second problem was insufficient scaffold permeability, which is a requirement for rapid renal solute exchange between the inner and outer compartment through transepithelial processes (i.e., passive diffusion and active transport). Earlier, we demonstrated the successful cellularization of biofunctionalized dialysis fibers, a

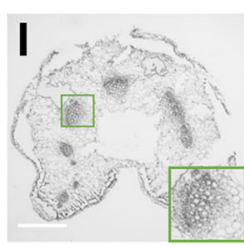

II

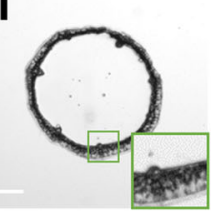

C

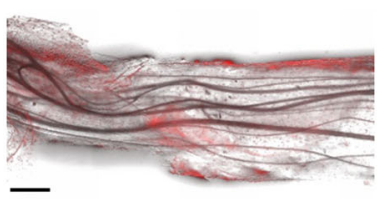

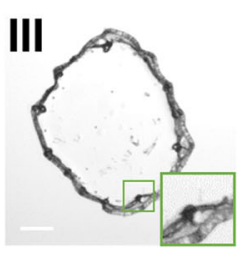
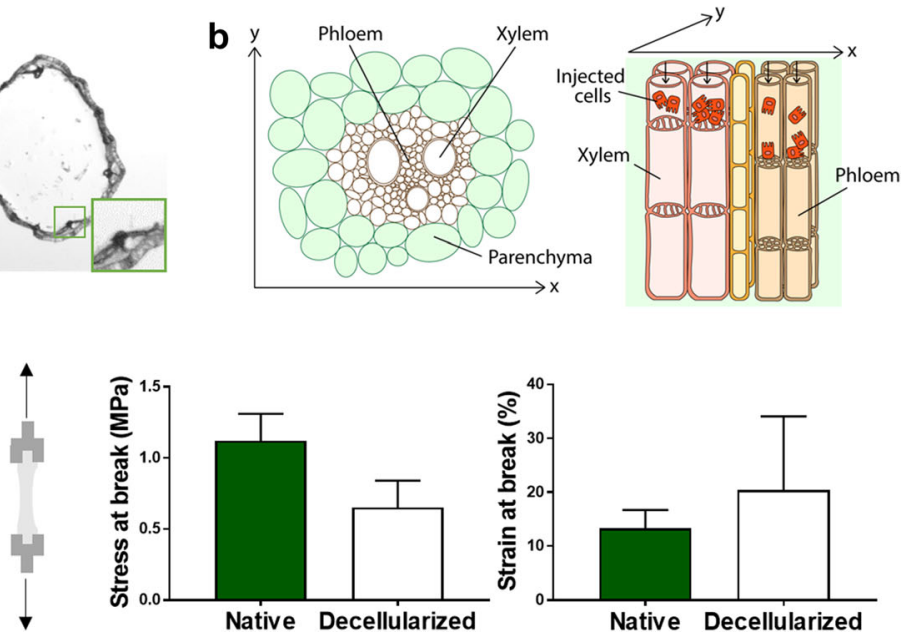

Fig. 3. Overview and anatomy of decellularized spinach and chive scaffolds for recellularization. a Cross-sections of (I) decellularized spinach petiole, (II) native chive, and (III) decellularized chive, with zoom on vascular bundles. b Schematic illustration of plant vascular bundles and the assumed anatomical restriction of luminal recellularization. $\mathbf{c}$ After one week in culture, recellularized chive disintegrated along its fiber direction; stress and strain at break were only testable with tensile loading in longitudinal direction $(n=4)$. Scale bars $=1 \mathrm{~mm}$ 
which allowed cellular transepithelial transport functionality $(21,22)$. Without cells, dialysis fibers leaked around $400 \mathrm{nmol}$ FITC-inulin per min per $\mathrm{cm}^{2}$ when perfused with $0.1 \mathrm{mg} / \mathrm{mL}$ for $10 \mathrm{~min}$ (23). With decellularized chive, we did not measure any FITC-inulin leakage after $10 \mathrm{~min}$.

\section{DISCUSSION}

With their broad range of complex structures, decellularized plant scaffolds provide a natural and inexhaustible source for advanced in vitro modeling and regenerative organ replacement strategies. After biofunctionalization, all kinds of human cell types can be seeded onto the scaffolds as demonstrated by Modulevsky and colleagues in 2014, by Gershlak and colleagues in 2017, and by us in the work at hand $(10,12)$. However, tissue-specific scaffold requirements for functionality and implantability, if intended, need to be carefully considered. In case of kidney tubule engineering, a thin scaffold sheet with complex tubular vasculature and a joint drainage, as provided by spinach leaves, would have met important anatomical requirements. Unfortunately, injected cells did not reach and distribute within the leaf vasculature, probably due to anatomical restrictions. Moreover, while we confirmed the general compatibility of decellularized plant scaffolds and kidney cells, the tissue-specific requirement of permeability for rapid solute diffusion was not met. Therefore, we consider neither spinach leaves nor chive as suitable for functional kidney tubule engineering. In addition, the observed tissue disintegration in culture suggests inappropriateness for implantation. An overview of our assessment is given in Fig. 4. Modulevsky et al. provided evidence for biocompatibility and implantability for apple-derived cellulose scaffolds, which are mainly composed of cell walls that contain pores and air pockets that facilitate cell invasion, the transport of nutrients and water, and vascularization in vivo (13). Next steps in this research group included scaffold examination for bone tissuespecific applicability (not yet peer-reviewed (24)). Moreover, very recently the US Food and Drug Administration recognized CelluBridge ${ }^{\mathrm{TM}}$, a plant-based spinal cord scaffold implant, as a Breakthrough Medical Device. While sponge-like plant-derived scaffolds might provide a suitable architecture for bone and spinal cord tissue, it is not suitable for kidney tubules that require scaffold compartmentalization and drainage capacity. With this paper, we want to highlight that unusual solutions often generically sound attractive but nevertheless require careful examination for purpose-specific evidence.

Despite limitations of plant leave structures for regenerative medicine due to likely tissue disintegration, drug development might still be able to benefit from engineered test models. With the provision of relatively low material stiffness, high water content, 3D structure and topographic guidance, cell lines can be cultured under more physiologically relevant conditions, which could translate into more predictive results. Insufficient scaffold permeability for renal transepithelial transport functionality does not exclude suitability for other cell models, such as endothelial cells and human pluripotent stem cell derived cardiomyocytes, which have shown normal functioning on decellularized spinach leaves (10). With regard to kidney tubule engineering, perhaps the combined use of plant-derived scaffold materials and other techniques could open doors for advanced in vitro modeling. Current technologies such as $3 \mathrm{D}$ printing, molding, and weaving could be used to integrate plant-derived structures and biomaterials for enhanced tissue engineering capabilities (25). For example, He et al. developed a microreplication method to transfer the microvascular network of leaf venation into hydrogels (26). This could be one way to take advantage of the complex plant structure while circumventing the limiting properties that we revealed with the work at hand. The various possibilities for the use of plantderived and other unconventional biomaterials have been reviewed elsewhere (27).
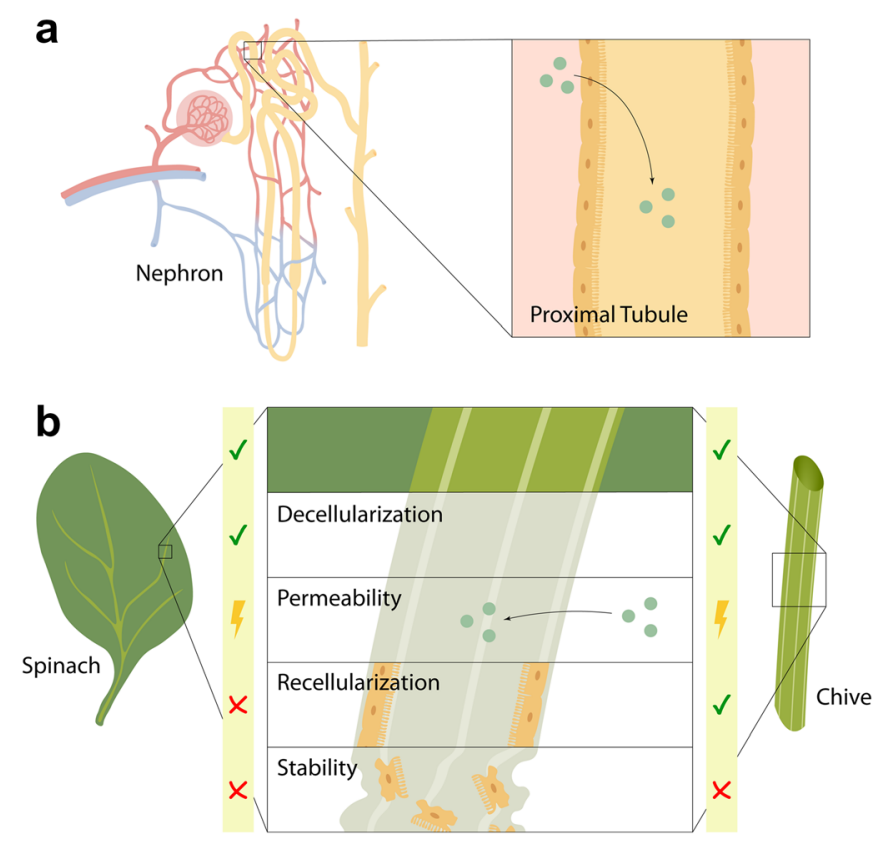

Fig. 4. Graphical overview of scaffold assessment for kidney tubule engineering. a Nephron, the functional unit of a kidney with zoom into the proximal tubule. b Assessment of decellularized spinach and chive scaffolds for kidney tubule engineering 


\section{CONCLUSION}

Although plant-derived cellulose scaffolds can be recellularized with mammalian cell types, tissue-specific requirements must be considered for proper tissue engineering. Here, we showed that decellularized spinach leaves and chive are unsuitable for kidney tubule engineering due to microanatomical limitations in the leaf venation for recellularization and limited scaffold permeability as premise for transepithelial solute exchange. Plant-derived biomaterials have still potential for advanced cell culture but need to be carefully selected and tested for tissue-specific functionality.

\section{ACKNOWLEDGMENTS}

We thank K.G.C. Westphal for the preparation of decellularized rat kidney slices. This project was financially supported by The Netherlands Organization for Scientific Research (NWO) as part of the Future Medicines Program (022.006.003).

\section{AUTHORS' CONTRIBUTIONS}

The current manuscript is, coincidentally, an all-women's effort within Utrecht Institute for Pharmaceutical Sciences. Intrigued by replacing animals in research, KJ conceived of the presented idea and performed and analyzed experiments. While performing internships as part of their undergraduate training, ME, CPC and SA assisted in experiments and analysis. Post-doctoral scientist JJ, and senior scientists TV and RM, supervised the findings and implications of this work, while bridging research at the divisions of Pharmaceutics and Pharmacology of the Institute. All authors discussed the results and contributed to the final manuscript.

\section{COMPLIANCE WITH ETHICAL STANDARDS}

Conflict of Interest The authors declare no conflict of interest.

Open Access This article is licensed under a Creative Commons Attribution 4.0 International License, which permits use, sharing, adaptation, distribution and reproduction in any medium or format, as long as you give appropriate credit to the original author(s) and the source, provide a link to the Creative Commons licence, and indicate if changes were made. The images or other third party material in this article are included in the article's Creative Commons licence, unless indicated otherwise in a credit line to the material. If material is not included in the article's Creative Commons licence and your intended use is not permitted by statutory regulation or exceeds the permitted use, you will need to obtain permission directly from the copyright holder. To view a copy of this licence, visit http://creativecommons.org/licenses/by/4.0/.

\section{REFERENCES}

1. Vranckx JJ, Hondt MD. Tissue engineering and surgery: from translational studies to human trials. Innov Surg Sci. 2017;2(4):189-202.
2. Edgar L, Pu T, Porter B, Aziz JM, La Pointe C, Asthana A, et al. Regenerative medicine, organ bioengineering and transplantation. Br J Surg. 2020;107(7):793-800.

3. Sthijns M, LaPointe VLS, van Blitterswijk CA. Building complex life through self-organization. Tissue Eng Part A. 2019;25(19-20):1341-6.

4. Davies JA, Chang CH. Engineering kidneys from simple cell suspensions: an exercise in self-organization. Pediatr Nephrol. 2014;29(4):519-24.

5. Porzionato A, Stocco E, Barbon S, Grandi F, Macchi V, De Caro R. Tissue-Engineered Grafts from Human Decellularized Extracellular Matrices: A Systematic Review and Future Perspectives. Int J Mol Sci. 2018;19(12).

6. Gilbert TW, Sellaro TL, Badylak SF. Decellularization of tissues and organs. Biomaterials. 2006;27(19):3675-83.

7. Fedecostante M, Westphal KGC, Buono MF, Sanchez Romero N, Wilmer MJ, Kerkering J, et al. Recellularized native kidney scaffolds as a novel tool in nephrotoxicity screening. Drug Metab Dispos. 2018;46(9):1338-50.

8. Orlando G, Booth C, Wang Z, Totonelli G, Ross CL, Moran E, et al. Discarded human kidneys as a source of ECM scaffold for kidney regeneration technologies. Biomaterials. 2013;34(24):5915-25.

9. Song JJ, Guyette JP, Gilpin SE, Gonzalez G, Vacanti JP, Ott HC. Regeneration and experimental orthotopic transplantation of a bioengineered kidney. Nat Med. 2013;19(5):646-51.

10. Gershlak JR, Hernandez S, Fontana G, Perreault LR, Hansen KJ, Larson SA, et al. Crossing kingdoms: using decellularized plants as perfusable tissue engineering scaffolds. Biomaterials. 2017;125:13-22.

11. Fontana G, Gershlak J, Adamski M, Lee JS, Matsumoto S, Le $\mathrm{HD}$, et al. Biofunctionalized plants as diverse biomaterials for human cell culture. Adv Healthc Mater. 2017;6(8).

12. Modulevsky DJ, Lefebvre C, Haase K, Al-Rekabi Z, Pelling AE. Apple derived cellulose scaffolds for 3D mammalian cell culture. PLoS One. 2014;9(5):e97835.

13. Modulevsky DJ, Cuerrier CM, Pelling AE. Biocompatibility of subcutaneously implanted plant-derived cellulose biomaterials. PLoS One. 2016;11(6):e0157894.

14. Fedecostante M, Onciu OG, Westphal KGC, Masereeuw R. Towards a bioengineered kidney: recellularization strategies for decellularized native kidney scaffolds. Int J Artif Organs. 2017;40(4):150-8.

15. Zhang H, Tasnim F, Ying JY, Zink D. The impact of extracellular matrix coatings on the performance of human renal cells applied in bioartificial kidneys. Biomaterials. 2009;30(15):2899-911.

16. Wilmer MJ, Saleem MA, Masereeuw R, Ni L, van der Velden TJ, Russel FG, et al. Novel conditionally immortalized human proximal tubule cell line expressing functional influx and efflux transporters. Cell Tissue Res. 2010;339(2):449-57.

17. Jansen K, Castilho M, Aarts S, Kaminski MM, Lienkamp SS, Pichler R, et al. Fabrication of kidney proximal tubule grafts using biofunctionalized electrospun polymer scaffolds. Macromol Biosci. 2019;19(2):e1800412.

18. Adamski M, Fontana G, Gershlak JR, Gaudette GR, Le HD, Murphy WL. Two methods for Decellularization of plant tissues for tissue engineering applications. J Vis Exp. 2018;135.

19. Petruzzello M. Xylem: Encyclopaedia Britannica, inc.; 2020 [Available from: https://www.britannica.com/science/xylem.

20. Britannica TEoE. Phloem: Encyclopaedia Britannica, inc.; 2020 [Available from: https://www.britannica.com/science/phloem.

21. Jansen J, De Napoli IE, Fedecostante M, Schophuizen CM, Chevtchik NV, Wilmer MJ, et al. Human proximal tubule epithelial cells cultured on hollow fibers: living membranes that actively transport organic cations. Sci Rep. 2015;5:16702.

22. Jansen J, Fedecostante M, Wilmer MJ, Peters JG, Kreuser UM, van den Broek $\mathrm{PH}$, et al. Bioengineered kidney tubules efficiently excrete uremic toxins. Sci Rep. 2016;6:26715.

23. Mihajlovic M, Fedecostante M, Oost MJ, Steenhuis SKP, Lentjes E, Maitimu-Smeele I, et al. Role of Vitamin D in Maintaining Renal Epithelial Barrier Function in Uremic Conditions. Int J Mol Sci. 2017;18(12). 
24. Leblanc Latour M. Plant-derived Cellulose Scaffolds for Bone Tissue Engineering. bioRxiv. 2020.

25. Hickey RJ, Pelling AE. Cellulose biomaterials for tissue engineering. Front Bioeng Biotechnol. 2019;7:45.

26. He J, Mao M, Liu Y, Shao J, Jin Z, Li D. Fabrication of natureinspired microfluidic network for perfusable tissue constructs. Adv Healthc Mater. 2013;2(8):1108-13.
27. Nguyen MA, Camci-Unal G. Unconventional tissue engineering materials in disguise. Trends Biotechnol. 2020;38(2):178-90.

Publisher's Note Springer Nature remains neutral with regard to jurisdictional claims in published maps and institutional affiliations. 